\section{Walter Edward Mickleburgh}

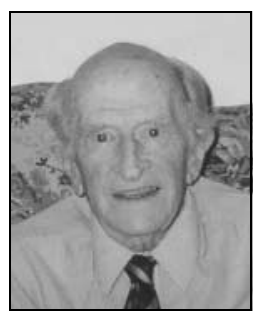

Formerly Director

of Mental Health in the

Australian Capital Territory

Walter 'Mick' Mickleburgh, born on 10

August 1922, died after a short illness at the age of 88 , on 13 May 2011. Born in rural Berkshire, Mick moved with his family to Slough, where his father had obtained work on the Great Western

Railway line. There, he gained entry to Slough Grammar School and later to the local polytechnic to study for a Bachelor of Science. This was put aside with the outbreak of the Second World War, in which Mick served as a reconnaissance pilot with the British army. After the war, he spent a further year helping in the reconstruction of Palestine.

Leaving the army with the rank of captain, Mick obtained a scholarship to study medicine at Aberdeen University, graduating in 1953. In the same year, he married June, who at the time was a nursing sister at Aberdeen Royal Infirmary. The two moved to Yorkshire, where Mick practised family medicine for 5 years.

While in Yorkshire, Mick became involved in the nuclear disarmament movement and developed an interest in mental health. He decided that the best place for him to follow these interests and to raise his growing family was Australia. With sponsorship from the South Australian Government, the Mickleburghs emigrated in 1959. Mick undertook his training in mental health in Adelaide and Melbourne, and in 1968 he was awarded a Fellowship of the Royal Australian and New Zealand College of Psychiatrists. He was subsequently awarded inaugural Membership of the Royal College of Psychiatrists of London in 1972 and in 1986 was elected to the Fellowship.

Mick also was at the forefront in the development of community care in South Australia and was a trendsetter in involving schools, police and other stakeholders in the provision of psychiatric services.

In 1974, Mick was appointed Director of Mental Health for the Australian Capital Territory (ACT), where he established new models of psychiatric care and care for people with intellectual disabilities. Within 5 years of taking up this appointment, he had set up an integrated community mental health service, with multidisciplinary teams providing comprehensive services from four regional community health centres.

Following his retirement from the Capital Territory Health Commission in 1985, Mick continued to practise in the ACT and in neighbouring New South Wales, principally at Calvary Hospital, Queanbeyan Community Mental Health Service and, up until his death, as a senior member of the ACT Mental Health Tribunal.

Mick was an eclectic psychiatrist, with a keen interest in endocrinology. He was ever expanding his academic pursuits and authored numerous articles on a broad range of subjects. Shortly before his death he signed off the final proofs for his first book Matters of Life and Death, which explores the existential concerns of many of his patients. This book will be published by Sid Harta Publishers late in 2011.

Mick is survived by June and their daughter, two sons and six grandchildren.

Ramesh Gupta

(in consultation with Mick's family) 